\title{
Mini Review on Research of T.W. Hermann as an Honorable
}

\section{Editor}

\section{Hermann TW*}

Department of Physical Pharmacy and Pharmacokinetics, Poznan University of Medical Sciences, Poland

*Correspondence author: Tadeusz Wladyslaw Hermann, Department of Physical

\section{Mini Review}

Volume 1 Issue 7

Received Date: November 01, 2017

Published Date: November 28, 2017

Pharmacy and Pharmacokinetics, Poznan University of Medical Sciences, 6 Swięcicki Str., 60-780 Poznan, Poland, E-mail:

hermann@ump.edu.pl

Keywords: Pharmacokinetics; Aminophenazone; Dimethylamine; Papaverine; oxidation products; Stability; Cytotoxic effect; Laplace transform

\section{Introduction}

I have initiated my research at the Department of Pharmaceutical Chemistry of Poznan University of Medical Sciences in 1960 on stability of drugs. According to my knowledge at that time I have been the first to discover dimethyl amine as a degradation product of aminophenazone aqueous solution 1:20 used in drug stores to prepare its liquid formulations [1]. Nowadays, that drug is removed from the list to be used in human medicine, because of a cancerous effect of its metabolite. Dimethylamine formed in the above aminophenazone aqueous solution becoming brownish yellow can cause marked irritation of skin, eyes, upper respiratory tract with conjunctivitis, sore throat, and coughing.

Later on I have spent a considerable time to study photo degradation processes involved on an instability of $2 \%$ papaverine hydrochloride injection solution, which on ageing is yellowish and even brownish [2]. I have isolated and developed the chemical structure (with help of Dr. U. Girreser of Ch. A. University of Kiel, Germany) of the compound which caused the brown color of the above degraded solution. The brown compound is 2,3,9,10tetramethoxy-12-oxo-12H-indolo[2,1-a] isoquinolinium chloride [3], whose cytotoxic behavior has been later discovered. I have also discovered another papaverine oxidation product of cytotoxic activity too [4], which was identified by us with $6 \mathrm{a}, 12 \mathrm{a}$-diazadiobenzo-[a,g] fluorenylium chloride [5]. These compounds were tested as eventual antitumor drugs. Stability investigations of papaverine injection solutions let me propose its stable formulation procedures. These require anaerobic conditions to seal the ampoules of suitable color with a suitable antioxidant dissolved in the solution. Methyl 4hydroxybenzoate was found as the best UV radiationprotective agent [6].

On my postdoctoral fellowship at the College of Pharmacy University of Florida in Gainesville with graduate research professor E.R. Garrett I have learnt theoretical bases of kinetics and pharmacokinetics of drugs. The so-called $\log \mathrm{k}-\mathrm{pH}$ profile was used to develop mechanism of solvolysis of different drugs. It is worthwhile to mention at least four significant publications [7-10].

The main topic of my research as the head of the Department of Physical Pharmacy and Pharmacokinetics since 1980 to 2007 was pharmacokinetics, therapeutic drug monitoring and bioavailability of drugs [11-14]. In order to solve pharmacokinetic differential equations one should be familiar with the integration techniques. However, the Laplace transform enables complex rate expressions to be manipulated easily by conventional algebraic techniques. Unfortunately, it is true only in the case of an open-one compartment body model [15]. With respect to two-compartment body model the resulting complicated transforms may be found only in an extensive table of Laplace transforms. Therefore, it is easier to use a general partial fraction theorem for obtaining inverse Laplace transforms [16]. 


\section{Open Access Journal of Pharmaceutical Research}

It is also not reasonable to forget to mention our publications on rationale design in the production of pharmaceutical formulations [17-19].

It is my belief that my long-lasting research experience can be a good source of knowledge for my new position as an honorable editor.

\section{References}

1. Pawełczyk E, Hermann TW (1963) Investigations of stability of aminophenazone aqueous solutions (in polish). Biul WAM Supp 1: 85-89.

2. Hermann TW, Lisowski Z, Wroński A (1965) Investigations of stability of papaverine hydrochloride injection solutions (in polish). Ibid 8(2): 235-241.

3. Girreser U, Hermann TW, Piotrowska K (2003) Oxidation and degradation products of papaverine. Part II [1]. Ivestigation on the photochemical degradation of papaverine solutions. Arch Pharm Pharm Med Chem (Weinheim) 336(9): 401-405.

4. Gałęzowska E, Masternak A, Rubiś B Czyrski A, Rybczyńska M, Hermann TW, et al. (2007) Spectroscopic study and G-quadruplex DNA binding affinity of two bioactive papaverine-derived ligands. Int J Biol Macromol 41(5): 558-563.

5. Hermann TW, Girreser U, Michalski P, Piotrowska K (2002) Oxidation and degradation products of papaverine. Part 1: Gadamer and Schulemann's papaverine synthesis revisited. Arch Pharm Pharm Med Chem (Weinheim) 335(4): 167-169.

6. Piotrowska K, Hermann TW, Pawelska A (2010) Photostabilization of papaverine hydrochloride solution. Acta Pol Pharm 67(4): 321-326.

7. Garrett ER, Hermann TW (1972) Prediction of stability of pharmaceutical preparations. XVII. Design of nonprecipitating injectable potassium canrenoate solution. J Pharm Sci 61(5): 717-722.

8. Garrett ER, Hermann TW, Hyuk-Koo Lee (1974) Kinetics and mechanism of solvolysis of 5iodocytosine. J Pharm Sci 63(6): 899-906.
9. Hermann $T$ (1974) Kinetics and mechanism of degradation of some 5-allylbarbituric acid derivatives. Part 1. Log $\mathrm{k}-\mathrm{pH}$ profile for 5,5diallylbarbituric acid solvolysis. Pharmazie 29(7): 453-461.

10. Hermann TW, Grześkowiak E (1983) Kinetics and mechanism of ftorafur ${ }^{\circledR}$ ftorafur solvolysis. Part 3. Log $\mathrm{k}-\mathrm{pH}$ profile for ftorafur solvolysis. ibid 38(9): 633-634.

11. Hermann T, Chrzanowska M, Michalewska D, Skibińska $\longleftarrow$ (1985) Pharmacokinetics of elimination of 6-mecaptopurine in the urine of children with acute lymphoblastic leukemia. Pol J Pharmacol Pharm 37(2): 209-216.

12. Hermann TW, Główka FK, Garrett ER (1993) Bioavailability of racemic ibuprofen and its lysinate from suppositories in rabbits. J Pharm Sci 82(11): 1102-1111.

13. Główka FK, Hermann TW, Zabel M (1998) Bioavailability of gliclazide from some formulation tablets. Int J Pharm 172(1): 71-77.

14. Flig E, Hermann TW, Zabel M (2000) Is bisacodyl absorbed at all from suppositories in man? Int J Pharm 196(1): 11-20.

15. Hermann TW (2015) Application of the Laplace transform in one-compartment pharmacokinetic model. Farm Pol 71(5): 289-294.

16. Hermann TW (2017) Application of Laplace transforms to a pharmacokinetic open twocompartment body model. Acta Poloniae Pharmaceutica-Drug Research 74(5): 1527-1531.

17. Hermann TW (1995) Recent research on bioavailability of drugs from suppositoeies. Int J Pharm 123(1): 1-11.

18. Neubert R, Hermann TW, Wieland I, Freesmeyer Ch (1990) Verhalten von Ibuprofen and von dessen Formulierungen im Resorptionsmodell. Pharmazie 45(5): 375-376.

19. Hermann TW, Dobrucki R, Piechocki S, Resztak M, Reh R (2005) Pharmaceutical availability of gliclazide from selected matrix formulations. Med Sci Monit 11(6): 181-199. 